\title{
Ultrastructural alterations in Plasmodium falciparum induced by chalcone derivatives
}

\author{
Shweta Sinha ${ }^{1}$, B. D. Radotra², Bikash Medhi ${ }^{3}$, Daniela I. Batovska ${ }^{4}$, Nadezhda Markova $^{4}$ and Rakesh Sehgal ${ }^{1 *}$ (D)
}

\begin{abstract}
Objective: Chalcones (1, 3-diaryl-2-propen-1-ones) and their derivatives are widely explored from the past decade for its antimalarial activity. To elucidate their mechanism of action on the malaria parasite, the ultrastructural changes with the action of these derivatives in different organelles of the parasite were studied in vitro. Infected RBCs [CQ sensitive (MRC-2) and CQ resistant (RKL-9) Plasmodium strain] were treated with three chalcone derivatives 1,2 and 3 and standard drugs, i.e., $C Q$ and artemisinin at twice their respective $\mathrm{IC}_{50}$ values for $24 \mathrm{~h}$ and then harvested, washed, fixed, embedded and stained to visualize ultra-structure changes before and after intervention of treatment under in vitro condition through transmission electron microscope.

Results: The ultrastructural changes demonstrate the significant disturbance of all parasite membranes, including those of the nucleus, mitochondria and food vacuole, in association with a marked reduction of ribosomes in the trophozoites and cessation of developing schizonts which suggest multiple mechanisms of action by which chalcone derivatives act on the malaria parasite. The present study opens up perspectives for further exploration of these derivatives in vivo malaria model to discover more about its effect and mechanism of action.
\end{abstract}

Keywords: Plasmodium falciparum, Transmission electron microscopy, Chalcones, Malaria, In vitro

\section{Introduction}

Malaria caused by Plasmodium falciparum species is the most noxious as they can infect all RBCs irrespective of their ages. The species is also most prevalent in the WHO African Region, leading to almost $99.7 \%$ malaria cases in 2018 [1]. Although there is a significant reduction in the number of malaria-infected cases and deaths over years of successful efforts through the malaria elimination programme, at the same time with the persistence evidence of growing $P$. falciparum resistance to artemisinin has led to a global threat [2-5]. Therefore, it is crucial to discover some fresh antimalarial drug entities which have the quality of effectiveness as well as efficiency towards

\footnotetext{
*Correspondence: sehgalpgi@gmail.com

${ }^{1}$ Department of Medical Parasitology, Post Graduate Institute of Medical

Education and Research, Chandigarh 160012, India

Full list of author information is available at the end of the article
}

malaria treatment [6] and can counter the rapidity of the drug resistance phenomenon of the parasite.

Chalcones (1,3-diaryl-2-propen-1-ones), a plant secondary metabolites is well known for its diverse pharmacological activity [7-9], including antimalarial activity [10]. It can also offer a huge repository of bioactive compounds with enormous molecular targets [11]. Earlier our group has reported three potent chalcone derivatives 1,2 and 3 with antimalarial activity, screened from a series of recently synthesized chalcone derivatives under in vitro conditions on both chloroquine-sensitive and chloroquine-resistant strains of Plasmodium. The study revealed even minor structural changes can increase the activity of a particular pharmacophore. Additionally, these derivatives act on the haeme degradation pathway of the malaria parasite, i.e., in a similar way as chloroquine does [11]. However, to better understand the effect and the mechanism by which these derivatives act on $P$.

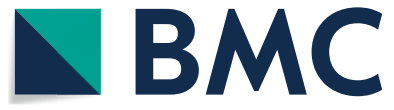

(c) The Author(s) 2020. This article is licensed under a Creative Commons Attribution 4.0 International License, which permits use, sharing, adaptation, distribution and reproduction in any medium or format, as long as you give appropriate credit to the original author(s) and the source, provide a link to the Creative Commons licence, and indicate if changes were made. The images or other third party material in this article are included in the article's Creative Commons licence, unless indicated otherwise in a credit line to the material. If material is not included in the article's Creative Commons licence and your intended use is not permitted by statutory regulation or exceeds the permitted use, you will need to obtain permission directly from the copyright holder. To view a copy of this licence, visit http://creativeco mmons.org/licenses/by/4.0/. The Creative Commons Public Domain Dedication waiver (http://creativecommons.org/publicdomain/ zero/1.0/) applies to the data made available in this article, unless otherwise stated in a credit line to the data. 
falciparum, an ultrastructure study was performed using the in vitro culture system.

\section{Main text \\ Materials and methods \\ Parasites}

The CQ-sensitive (MRC-2) and CQ-resistant (RKL-9) P. falciparum strains were maintained aseptically in continuous culture as mentioned earlier [12]. The P. falciparum culture was nurtured in A+ erythrocytes at 5\% haematocrit. The complete culture medium consisted of RPMI 1640 (with glutamine, but without $\mathrm{NaHCO}_{3}$ ), constituted of $5.94 \mathrm{~g} / \mathrm{L}$ of HEPES buffer, $1.00 \mathrm{~g} / \mathrm{L}$ dextrose, $40.00 \mathrm{mg} / \mathrm{L}$ of gentamycin. In addition, supplemented with $5 \% \mathrm{NaHCO}_{3}$ and $10 \%(\mathrm{v} / \mathrm{v})$ inactivated human $\mathrm{AB}+$ serum. Parasite cultures were kept at $37{ }^{\circ} \mathrm{C}$ with $90 \% \mathrm{~N}_{2}$, $5 \% \mathrm{O}_{2}$ and $5 \% \mathrm{CO}_{2}$, and the culture medium was changed at the interval of 22-24 h. Parasites were synchronized to the ring stage using 5\% D-sorbitol as described previously [13]. Parasite growth and multiplication were checked by thin smear Giemsa stained slides using a light microscope.

\section{Drugs and drug exposure}

The three chalcone derivatives 1,2 and 3 were synthesized as described previously by our group [11]. Chloroquine phosphate was obtained from Sigma Aldrich and artemisinin from IPCA. Stock solutions of three chalcone derivatives, chloroquine phosphate and artemisinin were separately prepared by dissolving each one of them in the diluted concentration of DMSO (1\%) to attain a concentration of $1.00 \mathrm{mg} / \mathrm{mL}$.

Before each experiment, cultures were expanded in sterile cell culture plates, maintaining less than $5 \%$ parasitaemia in 5\% haematocrit. A non-treated negative control was maintained separately in a different plate at the same culture condition, i.e., at $37{ }^{\circ} \mathrm{C}, 5 \% \mathrm{CO} 2,90 \% \mathrm{~N}_{2}, 5 \%$ $\mathrm{O}_{2}$. The ring-stage parasite-infected RBCs (strain MRC-2 \& RKL-9) were exposed to different drugs for $24 \mathrm{~h}$ at twice their respective $\mathrm{IC}_{50}$ values given in Table 1. After drug exposure, the $\mathrm{iRBC}$ were washed and lysed with $1 \mathrm{X}$ $\mathrm{RBC}$ lysis buffer to release parasite, which was further processed for transmission electron microscopy to assess parasite ultrastructure.

\section{Transmission electron microscopy}

Control and drug-treated parasites were washed with $1 \mathrm{X}$ PBS and suspended for $24 \mathrm{~h}$ with a mixture of a solution containing glutaraldehyde (2.5\%) and paraformaldehyde (4\%) in cacodylate buffer $(0.1 \mathrm{M})$ having $\mathrm{pH} 7.2$, followed by post-fixing with a mixture of osmium tetroxide $(1 \%$ $\mathrm{OsO}_{4}$ ) and potassium ferrocyanide $(0.8 \%)$ in cacodylate buffer $(0.1 \mathrm{M})$. The pellet down cells were then dehydrated in a graded concentration of acetone and embedded in Epoxy resin (EPON mixture with DMP in rubber moulds). Further kept for polymerization at $60{ }^{\circ} \mathrm{C}$ for $24 \mathrm{~h}$. Ultra-thin sections were cut on Ultracut-E ultramicrotome (Reichert-Jung, Germany) using a diamond

Table 1 IC $_{50}$ value of chalcone derivatives and standard drugs [11]

\begin{tabular}{|c|c|c|c|c|}
\hline Drugs/compound name & Structure & Series name & $\begin{array}{l}\text { MRC-2 (P. falciparum } \\
\mathrm{CQ}^{\mathrm{S}} \text { strain) IC50 }(\mu \mathrm{g} / \\
\mathrm{mL})\end{array}$ & $\begin{array}{l}\text { RKL-9 (P. falciparum } \\
\mathrm{CQ}^{\mathrm{R}} \text { strain) IC50 }(\mu \mathrm{g} / \\
\mathrm{mL})\end{array}$ \\
\hline $\begin{array}{l}\text { (E)-1-(2,5-Dimethoxyphenyl)-3-(4-methoxy- } \\
\text { phenyl)prop-2-en-1-one }\end{array}$ & & 1 & 0.13 & 0.14 \\
\hline $\begin{array}{l}\text { (E)-(3,4,5-Trimethoxyphenyl)-3-(4-methoxy- } \\
\text { phenyl)prop-2-en-1-one }\end{array}$ & & 2 & 0.35 & 0.19 \\
\hline $\begin{array}{l}\text { (E)-1-(3,4,5-Trimethoxyphenyl)-3-(3,4- } \\
\text { dimethoxyphenyl)prop-2-en-1-one }\end{array}$ & & 3 & 0.11 & 0.18 \\
\hline CQ & - & NA & 0.17 & ND \\
\hline Artemisinin $(\mathrm{ng} / \mathrm{mL})$ & - & NA & ND & 0.15 \\
\hline
\end{tabular}


knife and mounted on copper grids. The sections were double-stained with uranyl acetate and lead citrate and visualized in a ZEISS EM900 and in a JEOL 1200EX transmission electron microscope.

\section{Results and discussion}

In a search for novel compounds that would be effective blood schizonticides against both CQ sensitive and resistant $P$. falciparum, the action of chalcones derivatives at an ultra-structural level under in vitro conditions was studied. Infected RBCs [CQ sensitive (MRC-2) and CQ resistant (RKL-9) Plasmodium strain] were incubated without drug, taken as negative control, and treated with three chalcone derivatives 1,2 and 3 and standard $\mathrm{CQ}$ and artemisinin taken as positive control for CQ sensitive (MRC-2) and CQ resistant (RKL-9) strain at twice their respective $\mathrm{IC}_{50}$ values for $24 \mathrm{~h}$ and then harvested, washed, fixed, embedded and stained to visualize ultra-structure changes before and after intervention of treatment under in vitro condition on both the Plasmodium strain through transmission electron microscope.
Released Plasmodium from lysed RBC has shown in (Additional file 1: Figure S1).

At the ultrastructural level, the most conspicuous changes are seen in trophozoites at all stages of development. After $24 \mathrm{~h}$ of drug exposure, the mitochondria were swollen and there was the loss of membranes integrity. The endoplasmic reticulum is less conspicuous and ribosome numbers are markedly decreased (Fig. 1c-j) compared with parasites of the same stage from untreated control, having cytoplasm with well-distributed ribosomes and a clearly defined nucleus. However, food vacuole was well integrated on CQ treatment as compared to chalcones shown in (Fig. 1c, d).

Although the parasites are advancing towards schizogony, this process is being blocked. In Fig. 2. RKL-9 $(c-j)$, the nuclear membranes appear to have completely disappeared in places, making it difficult to distinguish between nuclear contents and the general cytoplasm. There is also a marked loss of endoplasmic reticulum and of ribosome density and content, especially in the parasite shown in Fig. 2. RKL-9 $(\mathrm{d}-\mathrm{j})$. In both types, a

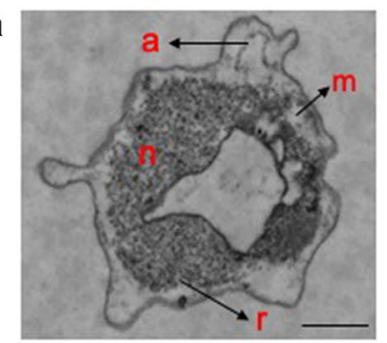

e

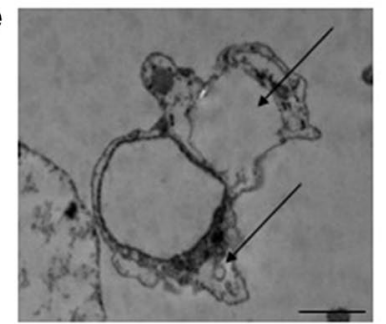

i

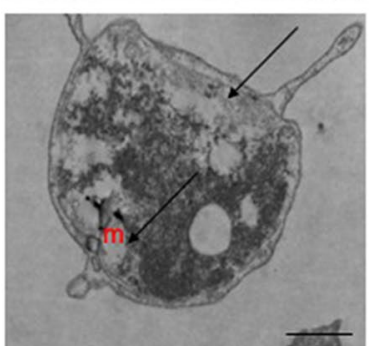

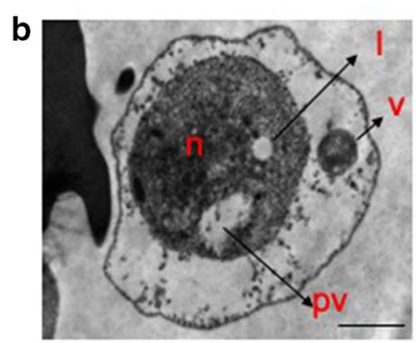

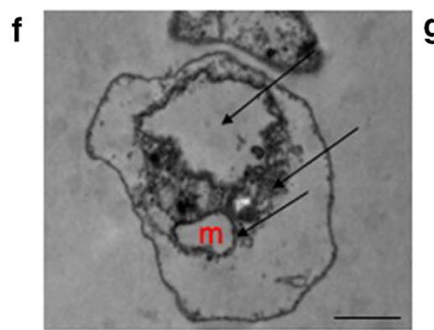

j

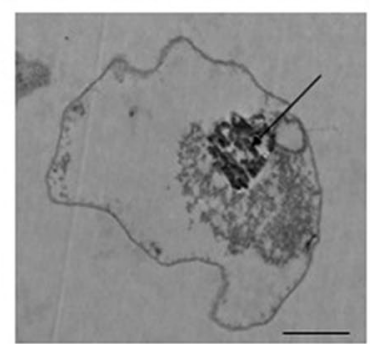

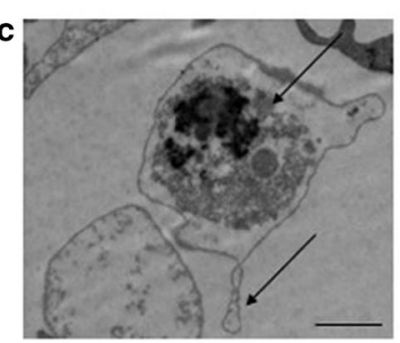

d

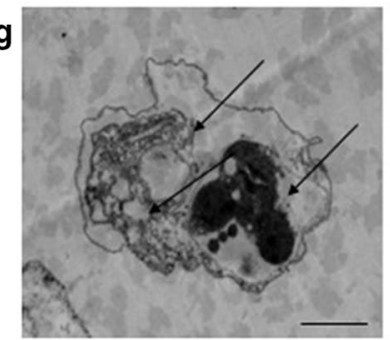

h

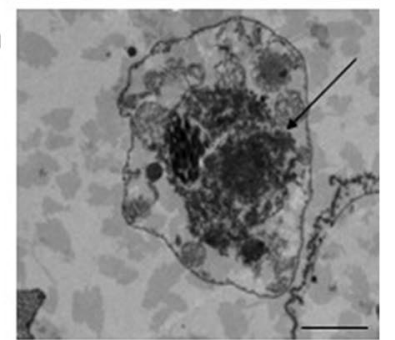

Fig. 1 Electron micrographs depicting the effect of chalcone derivatives on P. falciparum CQ sensitive (MRC-2) strain. a untreated control "early ring stage (early trophozoite)" and $\mathbf{b}$ untreated control "late ring stage (late trophozoite)" c, $\mathbf{d}$ CQ-treated; e, $\mathbf{f}$ compound 1-treated; $\mathbf{g}$, $\mathbf{h}$ compound 2-treated; i, j compound 3-treated. a Arrows represent appendages (a), ribosomes ( $r$ ) and, mitochondrion (m). b Arrows represent nucleus ( $\mathrm{n}$ ), lipid vacuole $(\mathrm{l})$, a cytostome with a forming food vacuole $(\mathrm{v})$, and pigment vacuole $(\mathrm{pv})$. c-j represents degenerative Plasmodium with condensed chromatin, vacuolation, membrane disintegration, swollen mitochondrion. The bar represents $800 \mathrm{~nm}-1 \mu \mathrm{m}$ 


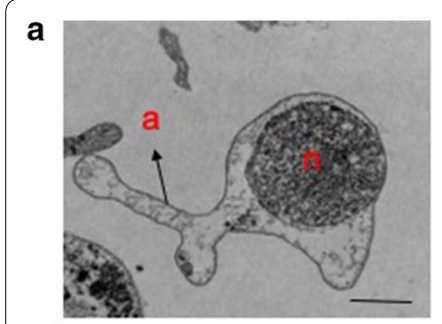

e

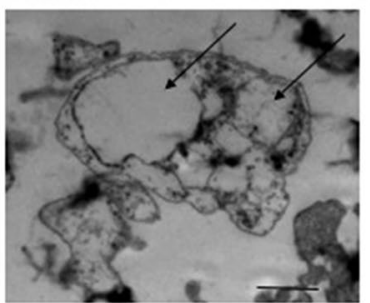

i

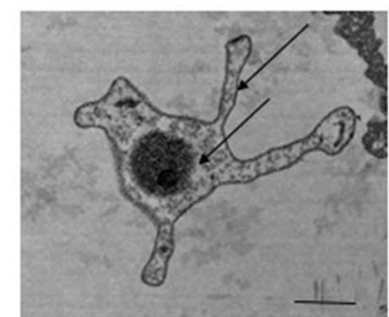

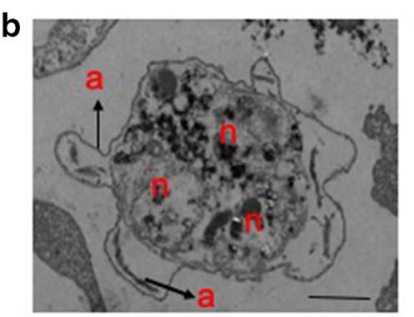

f
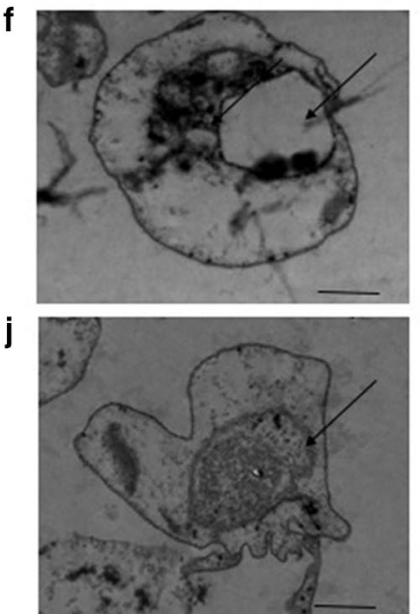
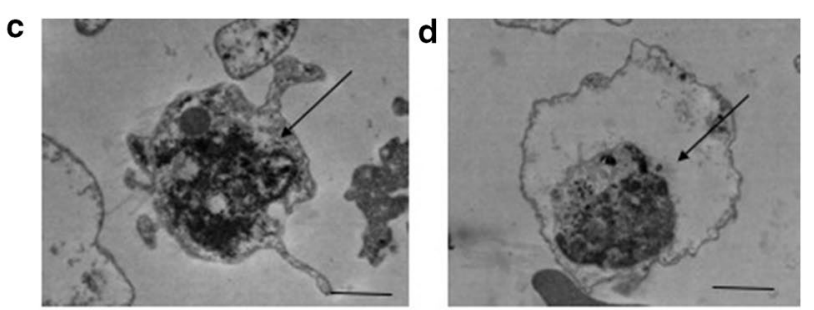

9
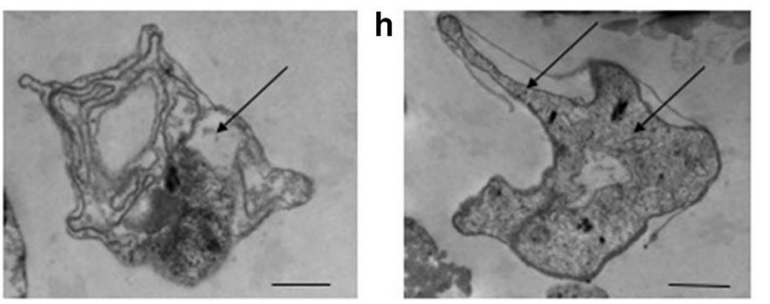

Fig. 2 Electron micrographs depicting the effect of chalcone derivatives on P. falciparum CQ resistant (RKL-9) strain. a untreated control "early ring stage (early trophozoite)" and $\mathbf{b}$ Untreated Control “Developing Schizont"; $\mathbf{c}, \mathbf{d}$ artemisinin-treated; e, $\mathbf{f}$ compound 1-treated; $\mathbf{g}$, h compound 2-treated; $\mathbf{i}, \mathbf{j}$ compound 3-treated. a Arrow indicates appendages, $\mathbf{b}$ arrows represent appendages (a) and multiple nuclei (n). $\mathbf{c}-\mathbf{j}$ Arrows show disintegrated forms of the malaria parasite, observed through darkly stained food vacuole $\mathbf{c}, \mathbf{d}, \mathbf{f}, \mathbf{i}$, larger vacuole formation ( $\mathbf{d}-\mathbf{j}$ ), disintegrated and disoriented parasite membranes and organelles, ribosome loss along with condensed nuclei (c-j). The bar represents $800 \mathrm{~nm}-1 \mu \mathrm{m}$

mitochondria are distended, nuclear membranes blebbed, and ribosomes are reduced. Numerous ribosomes are still visible but irregularly distributed within the cytoplasm which lacks the endoplasmic reticulum. Swollen mitochondria with varying degree of membrane irregularities is seen which shows similar results as compared with earlier report done on Leishmania parasite under the effect of oxygenated chalcones licochalcone A [14] and 2,4-dimethoxy-4'-butoxy-chalcone [15]. The peripheral parasite membrane is also partially disrupted, as is the membrane of the pigment vesicles. A major feature was the appearance of large vacuoles (Figs. 1 and $2 \mathrm{~d}-\mathrm{j}$ ). Schizogony has been interrupted. The process of merozoite membrane formation, both peripherally and around the nuclei, is clearly interrupted. The ultrastructural changes demonstrate the significant disturbance of all parasite membranes, including those of the nucleus, mitochondria, and endoplasmic reticulum, in association with a marked reduction of ribosomes in the trophozoites and developing schizonts which is supported by previous studies where drugs like artemisinin, dipyridamole, artesunate, quinine, and piperaquine showed more or less similar effects [16-18]. However, loss of knobs on drug treatment was not observed in both the Plasmodium strains due to RBC-free parasite. Knobs present on $P$. falciparum responsible for carrying antigens which benefit in parasite sequestration, would explain virulence and cytoadhesion ability [19]. Also, the food vacuole was intact but in condensed form in case of CQ-treated parasite, however, chalcone-treated parasites showed disintegrated food vacuole in mostly both CQ-sensitive and CQ-resistant strain. Additionally, evidence of darkly stained food vacuole in electron micrograph (Additional file 2: Figure S2) reveals interference in the haemoglobin degradation which ultimately lead to the death of the parasite [20]. Thus, suggest food vacuole may be the optimum target for chalcones which is further supported by our previous finding on significant reduction in hemozoin formation after chalcone treatment [11].

\section{Conclusion}

Chalcones and their derivatives are important scaffolds for providing various potent leads. The present ultrastructure study indicates food vacuole as the chief target 
site of these chalcone derivatives. However, the disintegration of other organelles, chromatin condensation and a marked reduction in ribosomes provide evidence about multiple mechanisms by which these chalcones exert its antiparasitic effect and it needs to be further validated through various biochemical, molecular and proteomics tools. Also, there is no such published study concerning the ultrastructural alteration induced on chalcone or chalcone derivative treatment on malaria parasite. Henceforth, the present study opens up perspectives for further exploration of these derivatives in vivo malaria models to discover more about its effect and mechanism of action.

\section{Limitations}

The stage dependent growth inhibition as well as time dependent growth inhibition of the parasite was not evaluated in the current study, which may provide clarity of kinetic and morphological changes inside the parasite under the influence of these chalcone derivatives.

\section{Supplementary information}

Supplementary information accompanies this paper at https://doi. org/10.1186/s13104-020-05132-z.

Additional file 1: Figure S1. Electron micrographs of released Plasmodium from lysed RBC depicting various stages in the asexual cycle of $P$. falciparum. RBC: Red Blood Cells; n: nucleus; pv: pigment vacuole; v: a cytostome with a forming food vacuole; I: lipid vacuole; $\mathrm{dm}$ : developing merozoites. The bar represents $800 \mathrm{~nm}$.

Additional file 2: Figure S2. Electron micrographs depicting the effect of treatment on hemozoin formation by malaria parasite compared to untreated control. A) untreated trophozoite, B) untreated developing schizont, C) \& D) (Q-treated and E) \& F) Compound-treated. Circle areas show haemoglobin degradation and formation of hemozoin crystals. CQ and Compound-treated, (C \& E) show darkly stained food vacuole due to interference in haemoglobin digestion; (D \& F) malaria parasites shows total disorganization with the residue of hemozoin crystals. The bar represents $600 \mathrm{~nm}-1 \mu \mathrm{m}$.

\section{Abbreviations}

CQ: Chloroquine; DMSO: Dimethyl sulfoxide; HEPES: 4-(2-hydroxyethyl)-1-piperazineethanesulfonic acid; $I C_{50}$ : The half maximal inhibitory concentration; $\mathrm{NaHCO}_{3}$ : Sodium bicarbonate; PBS: Phosphate buffer saline; RBC: Red Blood Cell.

\section{Acknowledgements}

We are thankful to Indian Council of Medical Research (ICMR), New Delhi for providing financial support in form of junior research fellowship and senior research fellowship to Shweta Sinha.

\section{Authors' contributions}

SS, RS, BM, BDR designed the study. SS and BDR performed experiments and analysis. DIB and NM contributed reagents and materials. SS, RS and BDR helped in the writing, reviewing, and editing of the manuscript. All authors read and approved the final manuscript.

\section{Funding}

No funding support has been provided in the design of the studies, data collection, analysis, interpretation of data and in writing of the manuscript from any funding agencies (public, commercial, or not-for-profit sectors).

\section{Availability of data and materials}

All data generated or analyzed during this study are included in this published article and its additional information files.

\section{Ethical approval and consent to participate}

The ethical approval was taken from Institute Ethics Committee, Project No. NK/1265/Ph.D/23991 at Post Graduate Institute of Medical Education and Research, Chandigarh, India for maintenance of $P$. falciparum strains in $A / B+$ ve erythrocytes and $A B+$ ve human serum.

\section{Consent for publication}

Not applicable.

\section{Competing interests}

The authors declare that they have no competing interests.

\section{Author details}

${ }^{1}$ Department of Medical Parasitology, Post Graduate Institute of Medical Education and Research, Chandigarh 160012, India. ${ }^{2}$ Department of Histopathology, Post Graduate Institute of Medical Education and Research, Chandigarh, India. ${ }^{3}$ Department of Pharmacology, Post Graduate Institute of Medical Education and Research, Chandigarh, India. ${ }^{4}$ Institute of Organic Chemistry with Centre of Phytochemistry, Bulgarian Academy of Sciences, Sofia, Bulgaria.

Received: 25 April 2020 Accepted: 6 June 2020

Published online: 15 June 2020

\section{References}

1. WHO. World malaria report 2019. Geneva: World Health Organization. http://www.who.int/malaria/publications/world-malariareport-2019/en/. Accessed 10 Feb 2020.

2. Noedl H, Se Y, Schaecher K, Smith BL, Socheat D, Fukuda MM. Artemisinin Resistance in Cambodia 1 (ARC1) Study Consortium. Evidence of artemisinin-resistant malaria in western Cambodia. N Engl J Med. 2008:359:2619-20.

3. Dondorp AM, Nosten F, Yi P, Das D, Phyo AP, Tarning J, Lwin KM, Ariey F, Hanpithakpong W, Lee SJ, et al. Artemisinin resistance in Plasmodium falciparum malaria. N Engl J Med. 2009;361:455-67.

4. Ashley EA, Dhorda M, Fairhurst RM, Amaratunga C, Lim P, Suon S, Sreng S, Anderson JM, Mao S, Sam B, Tracking Resistance to Artemisinin Collaboration, et al. Spread of artemisinin resistance in Plasmodium falciparum malaria. N Engl J Med. 2014;371:411-23.

5. Miotto O, Amato R, Ashley EA, Maclnnis B, Almagro-Garcia J, Amaratunga C, Lim P, Mead D, Oyola SO, Dhorda M, et al. Genetic architecture of artemisinin-resistant Plasmodium falciparum. Nat Genet. 2015;47:226-34.

6. Wells T, van Huijsduijnen R, Van Voorhis W. Malaria medicines: a glass half full? Nat Rev Drug Discov. 2015;14:424-42.

7. Nowakowska Z. A review of anti-infective and antiinflammatory chalcones. Eur J Med Chem. 2007;42:125-37.

8. Batovska DI, Todorova IT. Trends in utilization of the pharmacological potential of chalcones. Curr Clin Pharmacol. 2010;5:1-29.

9. de Mello TF, Bitencourt HR, Pedroso RB, Aristides SM, Lonardoni MV, Silveira TG. Leishmanicidal activity of synthetic chalcones in Leishmania (Viannia) braziliensis. Exp Parasitol. 2014;136:27-34.

10. Sinha S, Medhi B, Sehgal R. Chalcones as an emerging lead molecule for antimalarial therapy: a review. J Mod Med Chem. 2013;1:64-77.

11. Sinha S, Batovska DI, Medhi B, Radotra BD, Bhalla A, Markova N, Sehgal R. In vitro anti-malarial efficacy of chalcones: cytotoxicity profile, mechanism of action and their effect on erythrocytes. Malar J. 2019;8:421.

12. Trager W, Jensen JB. Human malaria parasites in Continuous culture. Science. 1976;93:673-5.

13. Lambros C, Vanderberg JP. Synchronization of P. falciparum erythrocytic stages in culture. J Parasitol. 1979;65:418-20. 
14. Zhai L, Blom J, Chen M, Christensen SB, Kharazmi A. The antileishmanial agent licochalcone $A$ interferes with the function of parasite mitochondria. Antimicrob Agents Chemother. 1995;39(12):2742-8.

15. Zhai L, Chen M, Blom J, Theander TG, Christensen SB, Kharazmi A. The antileishmanial activity of novel oxygenated chalcones and their mechanism of action. J Antimicrob Chemother. 1999;43(6):793-803.

16. Maeno Y, Toyoshima T, Fujioka H, Ito Y, Meshnick SR, Benakis A, Milhous WK, Aikawa M. Morphologic effects of artemisinin in Plasmodium falciparum. Am J Trop Med Hyg. 1993;49:485-91.

17. Akaki M, Nakano Y, Ito Y, Nagayasu E, Aikawa M. Effects of dipyridamole on Plasmodium falciparum-infected erythrocytes. Parasitol Res. 2002;88:1044-50

18. Sachanonta N, Chotivanich K, Chaisri U, Turner GD, Ferguson DJ, Day NP, Pongponratn E. Ultrastructural and real-time microscopic changes in $P$. falciparum-infected red blood cells following treatment with antimalarial drugs. Ultrastruct Pathol. 2011;35:214-25.

19. Rug M, Prescott SW, Fernandez KM, Cooke BM, Cowman AF. The role of KAHRP domains in knob formation and cytoadherence of $P$ falciparuminfected human erythrocytes. Blood. 2006;108:370-8.

20. Pulcini S, Staines HM, Lee AH, Shafik SH, Bouyer G, Moore CM, Daley DA, Hoke MJ, Altenhofen LM, Painter HJ, et al. Mutations in the Plasmodium falciparum chloroquine resistance transporter, PfCRT, enlarge the parasite's food vacuole and alter drug sensitivities. Sci Rep. 2015;5:14552.

\section{Publisher's Note}

Springer Nature remains neutral with regard to jurisdictional claims in published maps and institutional affiliations.
Ready to submit your research? Choose BMC and benefit from:

- fast, convenient online submission

- thorough peer review by experienced researchers in your field

- rapid publication on acceptance

- support for research data, including large and complex data types

- gold Open Access which fosters wider collaboration and increased citations

- maximum visibility for your research: over $100 \mathrm{M}$ website views per year

At BMC, research is always in progress.

Learn more biomedcentral.com/submissions 